\title{
Homenaje de la Facultad de Letras a José María Eguren
}

El 29 de abril se efectuó en el Salon de Actos cle la Facultad de Letras la primera de las actuaciones organizadas por el Instituto de Literatura en homenaje al poeta José María Eguren, con acasión del décimo aniversario de su fallecimiento.

Inició el acto de ese día el Decano de la Facul. tad, Doctor Aurelio Miró Quesada S., quien manifestó su cspecial complacencia por el significativo homenaje que constituia, en cierto modo, la apertura oficial del año académico de 1952 en los estudios de Letras. Agregó que, además de la labor docente $y$ diaria, $y$ de los trabajos de investigación eñosediversós Institutos, la facultad tenía el propósito de desarrollar un vasto programa de extención cultural, con exposiciones, conferencias, proyecciones cinematográficas y muestras de libros. EI primer acto se efectuaba bajo el signo poético y con el prestigio de la obra de Eguren.

Hizo luego una breve referencia a la alta calidad poética y a los matices más saltantes de la poesía equreniana, que dentro del homenaje preparado iban $\alpha$ ser analizados con el brillo de siempre y con la experta perspicacia de los Doctores José Jiménez Borja y Estuardo Núñez. Pero añadió que no podía menos que acentuar, ante los jóvenes estudiantes de San Marcos, tres notas esenciales de la persona y la obra de Eguren su finísimo sentido de nobleza y bondad, inseparable de su 
poesía, y que hace que tal vez no se lo expliquen totalmente quienes no tuvieron la ventura de llegar a tratarle; la consagración a su labor, desasido de todo reclamo circundante $y$ de los superficiales cúidados externos; y la capacidad de creación, que hace que su voz sea, no sólo una de las más puras, sino una de las más personales de nuestra galería ce postas. La poesía de Eguren - concluyó- nos ofrece por ello, además de un placer de orden estético, una lección de orden moral sin arrogancias, sin pasión, sin estruendo, nos ha dejado, limpiamente, y permanentemente, una Poesía de verdad.

El 7 de mayo el Dr. Estuardo Núnez, con la presidencia del Decano Dr. Aurelio Miró Quesada S. y la concurrencia del claustro y numeroso público, sostuvo su conterencia sobre "Jasé María Eguren, Poeta Clásico".

El 27 de junio -con los mismos auspiciosse realizó el homenaje de la poesia contemporánea del Perú al eminente poeta. El Dr. Jorge Puccinelli pronució las palabras liminares y luego ocuparon sucesivamente la tribuna del Salón de $A_{C}$ tos los poetas Enrique Peño Barrenechea, Augusto Tamayo, José Alfredo Hernández, Juan Ríos, Blanca Varela, Washington Delgado, Francisco Bendezú, Leopoldo Ehariarse, Alberto Escoliar y Lola Thorne, quienes dieron lectura a composiciones originales.

Tanto las conterencias de los doctores Jiménez Borja y Núñez como la presentación del acto y los poemas mencionados, se publican en este número. 